\title{
AN EARLY HUNTER-GATHERER SITE AT BAN NON WAT, NORTHEAST THAILAND
}

\author{
C.F.W. Higham \\ Department of Anthropology, University of Otago, P.O. Box 56, Dunedin, New Zealand \\ Email: charles.higham@otago.ac.nz
}

\section{R. Thosarat}

Retired, formerly Fine Arts Department of Thailand paetraboat@yahoo.co.th

Keywords: Ban Non Wat, hunter-gatherer occupation, late Pleistocene, radiocarbon determinations

\begin{abstract}
The inland plains of Southeast Asia are a void in terms of early occupation by huntergatherers. Two radiocarbon determinations from basal Ban Non Wat on the Khorat Plateau date a shell midden and possibly associated human and deer remains between 18,00020,000 years ago.
\end{abstract}

There is abundant documentation on Pleistocene hunter-gatherer occupation of upland rock shelters in mainland Southeast Asia. Maritime hunter-gatherer sites are also found when an elevated sea level in the 3rd millennium BC formed raised beaches (Hung 2019). However, hunter-gatherer occupation of the extensive interior plains is virtually unknown, despite the abundance of resources that would have been available. Fieldwork designed to identify inland hunter-gatherer sites would need extraordinary luck rather than any judgement, because settlements are likely to be buried deep under alluvial deposits, following both natural processes and the impact of deforestation.

This brief paper reports on a cultural deposit in the lowest cultural context at the site of Ban Non Wat. Located in the upper reaches of the Mun River catchment on the Khorat Plateau of Northeast Thailand, it is best known for the long and well-documented sequence that began with a series of flexed burials, continued with occupation and mortuary remains of early rice farmers, and then into multiple phases of the Bronze and Iron Ages. In November 2007, we encountered in the southeastern corner of square E9, a deep basal shell midden that just extended into the excavated area (Fig. 1). In the same layer, there was a complete skeleton of Cervus eldi, a medium-sized deer, and the skeleton of an infant the bones of which, unlike all others in this part of the site, were covered in a thick crust of concretions (Figs 2 and 3). The midden comprised the gastropod Filopaludina, which is adapted to freshwater streams and ponds.

Since we uncovered these finds on the last day of the excavation season, we were unable to extend the excavation to ascertain the extent of the midden or seek more remains of this context. However, we sent a shell sample to the Oxford radiocarbon laboratory for AMS dating, the

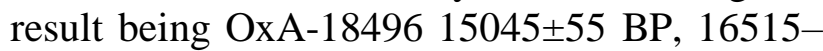
16122 cal. BC. We initially thought that this might have been a rogue date, or that this was a natural deposit of shellfish. However, we have not set aside this singular conjunction of human and cervid skeletons and the shell midden, and recently sent a second sample of Filopaludina shell to the Oxford laboratory. The result is OxA-38085 16310 \pm 65 BP, 17971-17559 cal. $\mathrm{BC}$.

We therefore suggest that the site of Ban Non Wat was in all probability, occupied between 18,000 to 20,000 years ago by a group of hunter-gatherers, and propose that the inland plains of Southeast Asia might well have been a widely occupied during the later Pleistocene period. 


\section{ACKNOWLEDGEMENTS}

We acknowledge the financial support of the Marsden Fund, New Zealand, and Earthwatch and its Research Corps. Without the support of the villagers of Ban Non Wat, the excavations would never have taken place.

\section{REFERENCE}

Hung, H-C. 2019. Prosperity and complexity without farming: the South China coast, c. 5000-3000 BC. Antiquity 93:325-341.

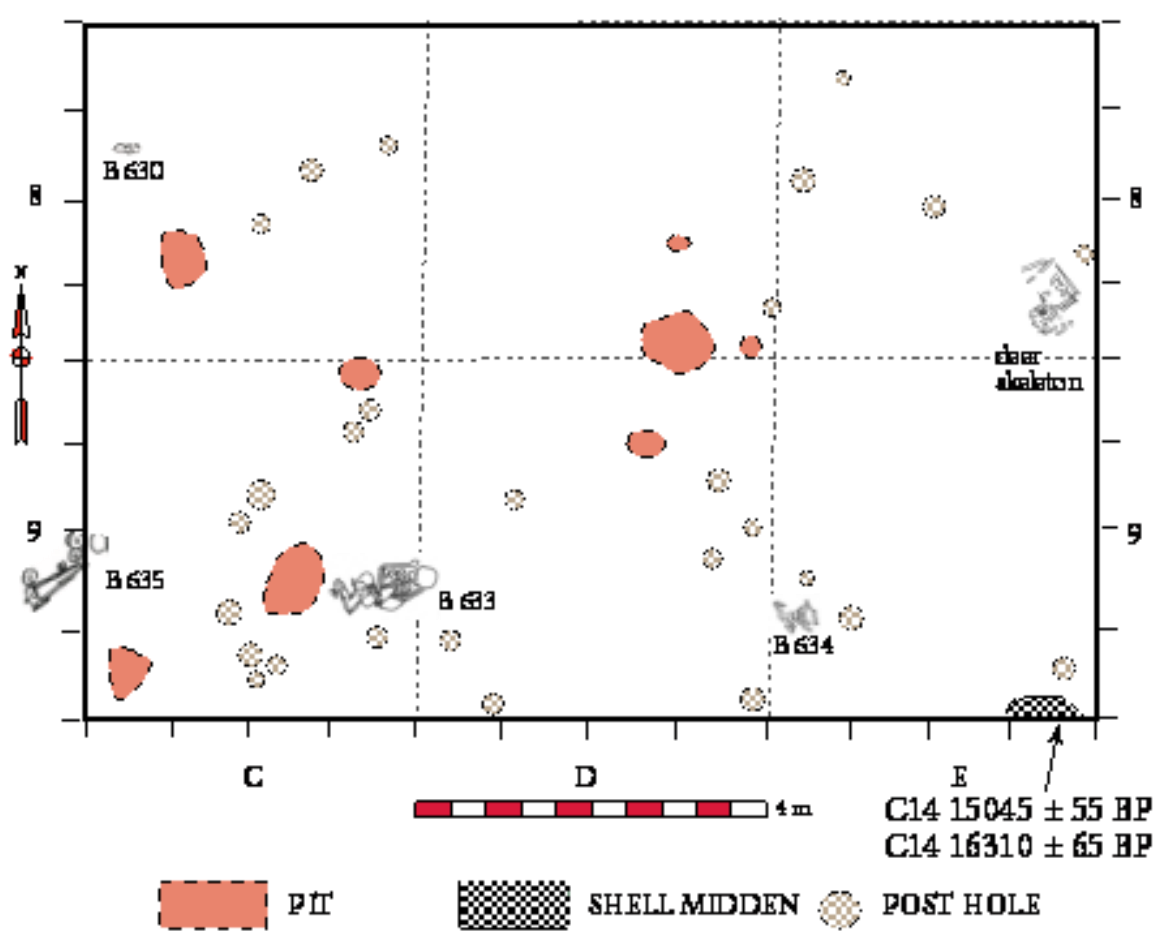

Figure 1. Plan of the excavated area in square E9 at Ban Non Wat showing the location of the dated shell midden, the deer skeleton and burial 630. Illustration by C.F.W. Higham. 


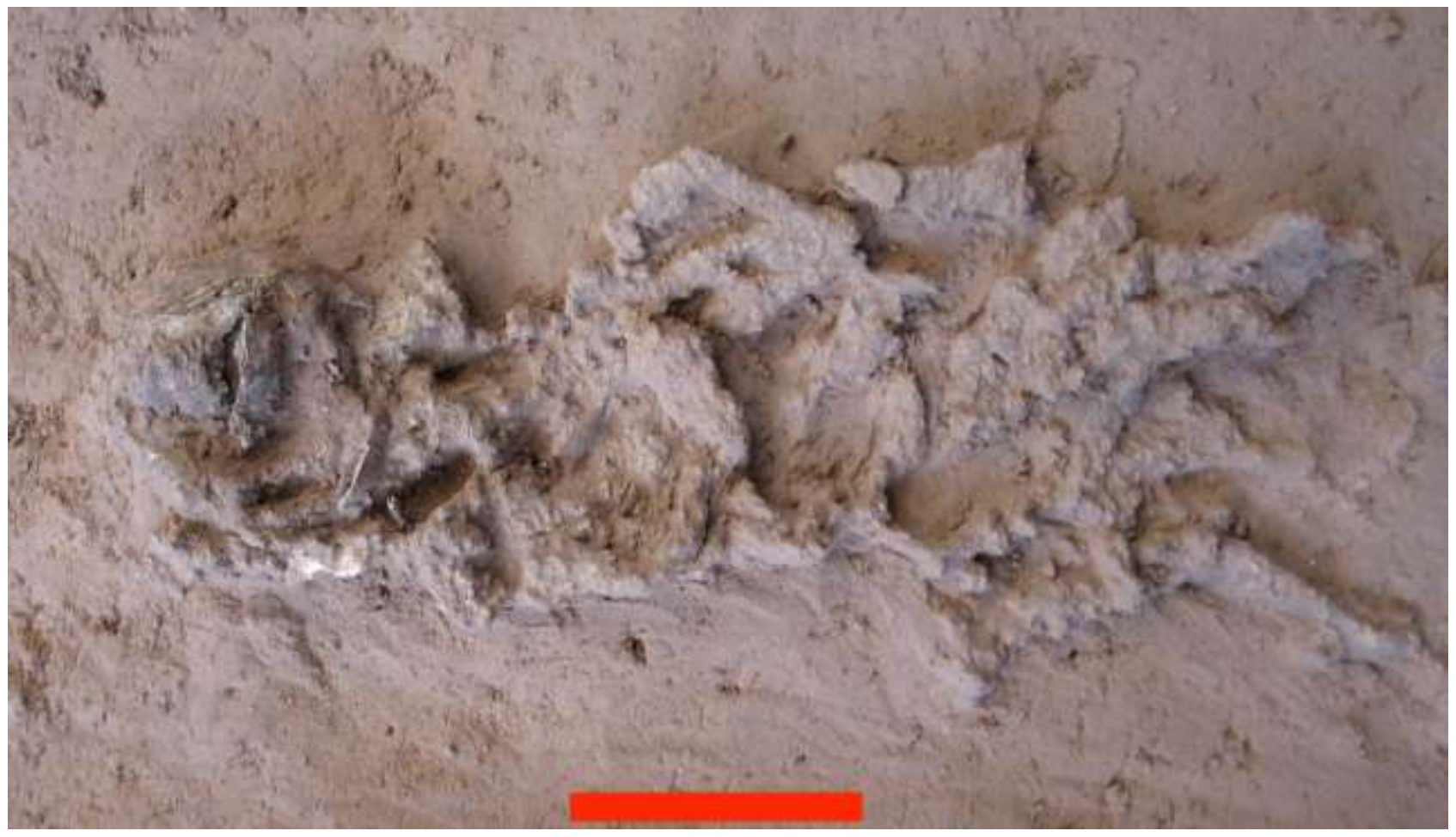

Figure 2. Burial 630 at Ban Non Wat, with the infant bones covered in concretions. Photograph by C.F.W. Higham. 


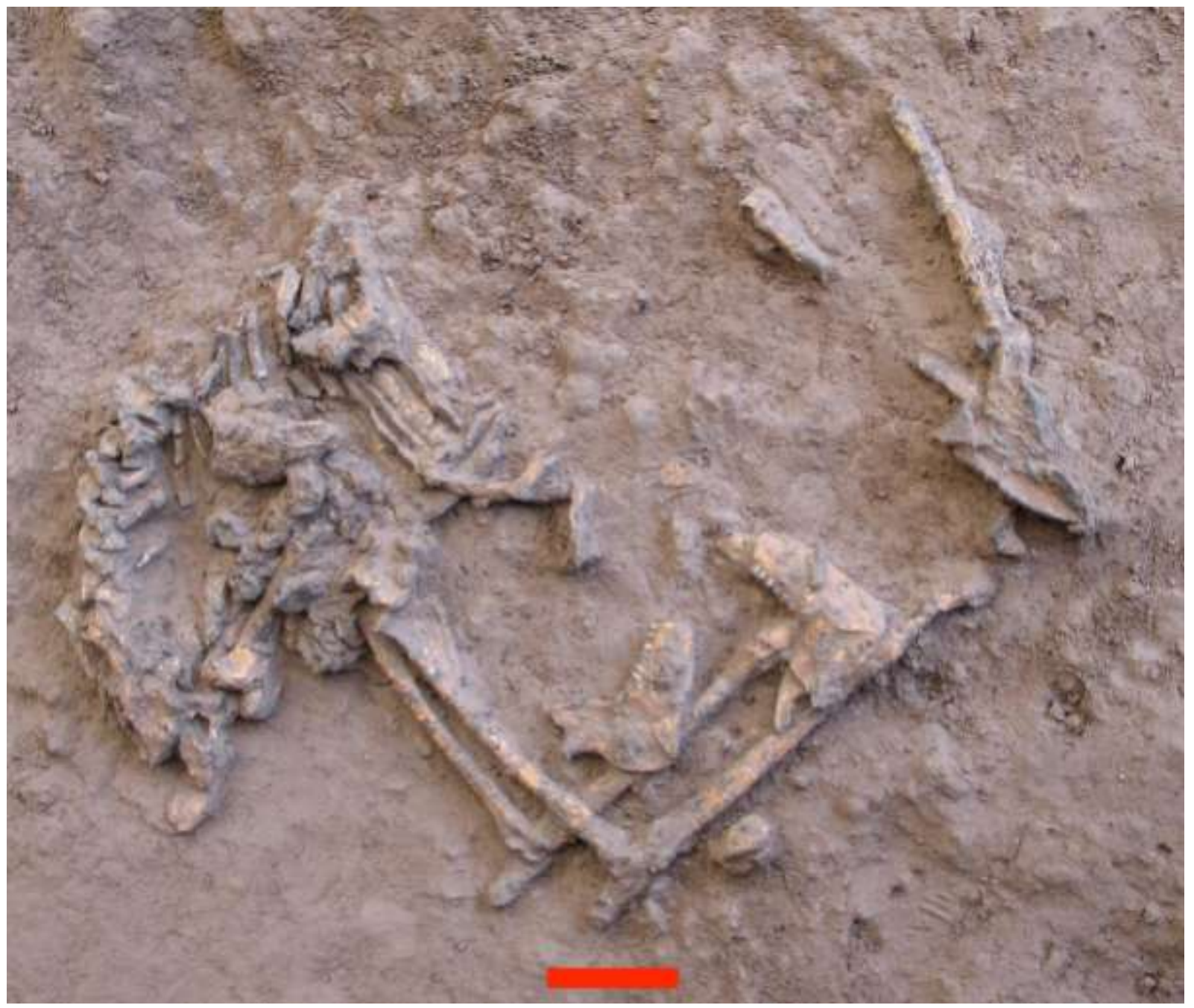

Figure 3. A complete skeleton of a deer from basal Ban Non Wat. Photograph by C.F.W. Higham. 